\title{
Spontaneous emission from saturated parametric amplifiers
}

\author{
Rottwitt, Karsten; Ott, Johan Raunkjær; Steffensen, Henrik; Ramachandran, Siddharth
}

Published in:

11th International Conference on Transparent Optical Networks, 2009. ICTON '09

Link to article, DOI:

10.1109/ICTON.2009.5185056

Publication date:

2009

Document Version

Publisher's PDF, also known as Version of record

Link back to DTU Orbit

Citation (APA):

Rottwitt, K., Ott, J. R., Steffensen, H., \& Ramachandran, S. (2009). Spontaneous emission from saturated parametric amplifiers. In 11th International Conference on Transparent Optical Networks, 2009. ICTON '09 (pp. 1-2). IEEE. https://doi.org/10.1109/ICTON.2009.5185056

\section{General rights}

Copyright and moral rights for the publications made accessible in the public portal are retained by the authors and/or other copyright owners and it is a condition of accessing publications that users recognise and abide by the legal requirements associated with these rights.

- Users may download and print one copy of any publication from the public portal for the purpose of private study or research.

- You may not further distribute the material or use it for any profit-making activity or commercial gain

- You may freely distribute the URL identifying the publication in the public portal 


\title{
Spontaneous Emission from Saturated Parametric Amplifiers
}

\author{
Karsten Rottwitt, Johan Raunkjær Ott, Henrik Steffensen and Siddharth Ramachandran \\ DTU Fotonik, Department of Photonics Engineering, Technical University of Denmark \\ Building 343, 2800 Kgs. Lyngby, Denmark \\ e-mail: karo@fotonik.dtu.dk
}

\begin{abstract}
Noise performance of parametric amplifiers is typically calculated assuming un-depleted operation. However, in many applications especially when applied as regenerative amplifiers in systems based on phase shift keyed modulation schemes, this assumption is not valid. Here we show the impact on accumulated spontaneous emission for a parametric amplifier operated in saturation.
\end{abstract}

\section{INTRODUCTION}

The fiber optical parametric amplifier (FOPA) has proven its validity as a regenerator in transmission systems based on phase shift keyed modulation formats [1]. The reason is that, the amplifier has a fast response time and at the same time may operate in saturation. Consequently, the FOPA is capable of acting as a limiter, which means that the amplitude of individual pulses will be nearly identical after propagation through the amplifier. This eventually leads to a reduction in the distortion of the phase information keyed onto the pulses.

The gain performance of the FOPA as well as the gain saturation is well described by solving coupled amplitude equations [2]. However, the noise performance of the amplifier is more complicated. This is caused by several issues including pump and signal cross talk, spontaneous Raman scattering and parametric fluorescence, in the following referred to as spontaneous emission. Physically, these noise contributions may be difficult to decouple, however in this work we treat the problem numerically and focus solely on the spontaneous emission.

Quantum mechanically it has been demonstrated that the lower limit with respect to spontaneous emission leads to a $3 \mathrm{~dB}$ degradation in the electrical signal to noise ratio of a signal amplified in a FOPA, see for example by C. McKinstrie and co-workers [3]. This limit holds in the assumption of high gain in addition to un-saturated gain. In addition, it has also been demonstrated, by K. Inoue and co-workers that the signal to noise ratio may be improved when the amplifier is operated in saturation [4]. However, for many applications it is not sufficient only to look at the signal to noise ratio, also the degradation of the phase needs to be described. Finally, the analysis of the FOPA is further complicated by the fact that the gain spectrum depends upon the fiber length and the signal and the pump power levels.

\section{RESULTS AND DISCUSSION}

In the following we limit our work to a single pumped parametric amplifier. That is, the amplifier configuration consists of a pump beam at a specific wavelength, in the following $1564 \mathrm{~nm}$. This wavelength is determined by the wavelength at which the fiber has zero group velocity dispersion. The pump is wavelength multiplexed together with a signal, which we assume is scanned across the entire wavelength range over which the amplifier provide gain. There is no idler present at the input.

When energy is transferred from the pump to the signal, the signal is accompanied by spontaneous emission. In the following this is modelled by assuming that a single photon with an arbitrary phase is added to the input signal. In addition, the idler is assumed to grow from a single photon at the input having an arbitrary phase. The pump is treated classically as a pump power with well defined amplitude and phase.

At the output of the amplifier, the signal power and the phase of the signal is evaluated. From this, the average output power is evaluated. This defines the average output gain of the amplifier as the average output signal power relative to the input signal power. The average gain of a $500 \mathrm{~m}$ long amplifier, pumped using $1 \mathrm{~W}$ of pump power at $1564 \mathrm{~nm}$ is shown in Fig. 1. The background loss of the fiber has been neglected, and a nonlinear strength $\gamma$ of $10 \mathrm{~W}^{-1} \mathrm{~km}^{-1}$ and a dispersion slope of $0.015 \mathrm{ps} / \mathrm{nm}^{2} \cdot \mathrm{km}$ has been used.

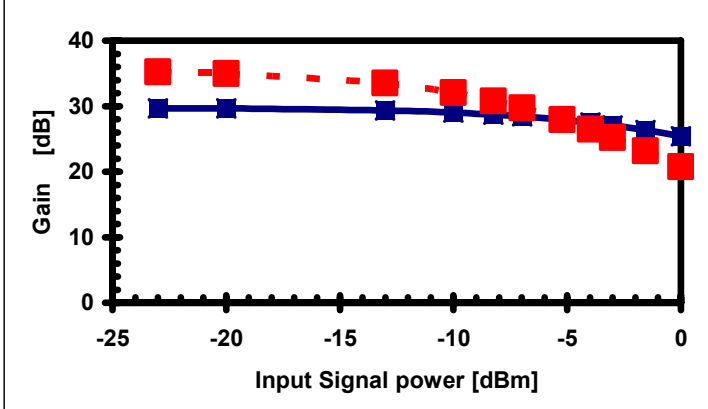

Figure 1. Gain as a function of input signal power for two different signal wavelengths. Solid trace: $1575 \mathrm{~nm}$, Dashed trace $1585 \mathrm{~nm}$. Other parameters as in the main text. 
In addition to the average gain, the ratio of the squared average signal power relative to the variance of the optical signal power is evaluated. We define this ratio as the signal to noise ratio (SNR). The degradation of the signal to noise ratio from the input to the output of the $500 \mathrm{~m}$ long FOPA, described in Fig. 1, as a function of the input signal power is shown in Fig. 2.

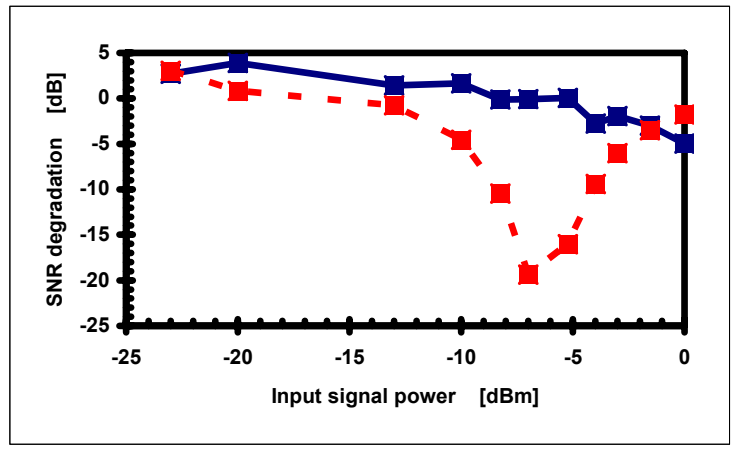

Figure 2. SNR degradation as a function of input signal power for two different signal wavelengths, the solid trace correspond to $1575 \mathrm{~nm}$ whereas the dashed trace correspond to $1585 \mathrm{~nm}$.

It is noted that the SNR drops dramatically for input powers exceeding $-15 \mathrm{dBm}$. In fact the SNR has improved by nearly $20 \mathrm{~dB}$ for a signal power close to $-7 \mathrm{dBm}$. As the signal power is further increased, the SNR again becomes degraded as the signal is amplified by the FOPA as the input signal power approaches $0 \mathrm{dBm}$. This agrees with K. Inoue and T. Mukai [4].

In addition to the degradation in the SNR the degradation in the phase was calculated as the squared mean phase relative to the variation in the phase. This however, showed only a constant degradation which was close to $3 \mathrm{~dB}$ within the uncertainty caused by the finite number of input phases. Constellation diagrams show how the probability density functions of the amplitude and the phase of signals change as the amplifier is saturated.

\section{CONCLUSION}

The signal to noise ratio of a FOPA has been predicted showing a clear improved signal to noise ratio when operated in depletion. Nearly $20 \mathrm{~dB}$ of improvement in the signal to noise ratio has been demonstrated in a specific example when the amplifier is operated under optimum conditions. The performance in the signal to noise ratio has been shown clearly to depend on the amplifier design and operating conditions.

\section{ACKNOWLEDGEMENTS}

EOARD is thanked for financial support under the grant: FA8655-06-13094

\section{REFERENCES}

[1] C. Peucheret, M. Lorenzen, J. Seoane, D. Noordegraaf, C.V. Nielsen, K. Rottwitt, L. Grüner-Nielsen, "Dynamic range enhancement and amplitude regeneration in single pump fibre optic parametric amplifiers using DPSK modulation," in Proc. ECOC'08.

[2] J. Hansryd, P.A. Andrekson, M. Westlund, Li Jie, P.-O Hedekvist, "Fiber-based optical parametric amplifiers and their applications," IEEE J. of Selected Topics in Quantum Electronics, vol. 8, no. 3, p. 506, (2002).

[3] C.J. McKinstrie, S. Radic and M.G. Raymer, "Quantum noise properties of parametric amplifiers driven by two pump waves," Opt. Express, vol. 12, no. 12, p. 5037, (2004).

[4] K. Inoue and T. Mukai, "Experimental study on noise characteristics of a gain-saturated fiber optical parametric amplifier,” JLT, vol. 20, no. 6, p. 969, (2002). 